\begin{tabular}{ll|l} 
Case Reports in & \multicolumn{2}{c}{ Case Rep Gastroenterol 2013;7:82-88 } \\
\cline { 2 - 3 } Gastroenterology & $\begin{array}{l}\text { DOI: 10.1159/000350187 } \\
\text { Published online: March 7, 2013 }\end{array}$ & $\begin{array}{l}\text { ○ 2013 S. Karger AG, Basel } \\
1662-0631 / 13 / 0071-0082 \$ 38.00 / 0 \\
\text { www.karger.com/crg }\end{array}$ \\
\hline & $\begin{array}{l}\text { This is an Open Access article licensed under the terms of the Creative Commons Attribution- } \\
\text { NonCommercial-NoDerivs 3.0 License (www.karger.com/OA-license), applicable to the } \\
\text { online version of the article only. Distribution for non-commercial purposes only. }\end{array}$
\end{tabular}

\title{
Pulmonary Embolism in a Patient with Eosinophilic Esophagitis: Causal or Coincidental?
}

\author{
Patricia D. Jones ${ }^{a, b}$ Stephan Moll ${ }^{c}$ Evan S. Dellon ${ }^{a, b}$ \\ ${ }^{a}$ Center for Esophageal Diseases and Swallowing and ${ }^{b}$ Center for Gastrointestinal Biology \\ and Disease, Division of Gastroenterology and Hepatology, and ${ }^{\mathrm{C}} \mathrm{Hemophilia}$ and \\ Thrombosis Center, Division of Hematology-Oncology, University of North Carolina \\ School of Medicine, Chapel Hill, N.C., USA
}

\section{Key Words}

Eosinophilic esophagitis · Venous thromboembolism · Pulmonary embolism · Deep vein thrombosis · Inflammation

\begin{abstract}
Eosinophilic esophagitis is a chronic immune-mediated disease characterized by infiltration of the esophageal mucosa with eosinophils and concomitant esophageal dysfunction. Though there are well-described associations between certain chronic inflammatory conditions and venous thromboembolism, there have been no reports of venous thromboembolism occurring in eosinophilic esophagitis. We report the case of a 33-year-old man with severe eosinophilic esophagitis resulting in recurrent esophageal strictures who was unresponsive to oral viscous budesonide therapy, and who developed an isolated pulmonary embolism in the absence of risk factors for venous thromboembolism. We then discuss potential mechanisms for venous thromboembolism in eosinophilic esophagitis, such as inflammation-mediated hypercoagulability, hypereosinophilia, and immunoglobulin E-mediated platelet activation.
\end{abstract}

\section{Introduction}

Eosinophilic esophagitis (EoE) is an antigen/immune-mediated, chronic inflammatory condition of the esophagus defined by symptoms of esophageal dysfunction and a marked eosinophilic infiltrate in the esophageal mucosa [1]. For the diagnosis of EoE, one must have at least one biopsy specimen with $\geq 15$ eosinophils per high-power field after a high-dose

130 Mason Farm Rd., UNC-CH

Chapel Hill, NC 27599-7080 (USA)

E-Mail edellon@med.unc.edu 
proton pump inhibitor trial and symptoms related to esophageal dysfunction. These range from feeding difficulties, vomiting and abdominal pain in infants and toddlers to dysphagia and food impactions in older patients. Common endoscopic findings in EoE include linear furrows, fixed or transient esophageal rings, whitish exudates, edema, diffuse esophageal narrowing and crepe paper esophagus, the term given to mucosa which is thin, fragile and tears easily [1]. EoE can be treated with topical corticosteroids such as fluticasone or oval viscous budesonide, and in rare cases with systemic corticosteroids if there is severe EoE manifested by a small-caliber esophagus, weight loss or hospitalization [1].

Systemic inflammatory states are known risk factors for venous thromboembolism (VTE), including inflammatory bowel disease [2-4] and rheumatoid arthritis [5] through a variety of proposed mechanisms including inflammation-mediated hypercoagulability, upregulation of procoagulant proteins and downregulation of anticoagulant proteins. EoE is currently thought to cause local rather than systemic inflammation [1]. However, in this report we describe a case of pulmonary embolism (PE) without evidence of deep venous thrombosis in a patient with severe EoE. This case raises the question of whether disease states with local inflammation alone might also be associated with VTE, and in this article, we explore potential mechanisms by which patients with EoE might develop venous thromboembolic disease.

\section{Case Report}

A 33-year old man with a known history of EoE presented for endoscopy for recurrent dysphagia. He was diagnosed 2 years prior to presentation as per consensus guidelines [1] after emergent upper endoscopy for an acute food impaction. He reported a life-long history of dysphagia with intermittent food impactions as well as allergic rhinitis and sinusitis. He had no other medical problems and a previous complete blood count was normal with no evidence of peripheral eosinophilia (white blood count $5.3 \times 10^{9} / \mathrm{l}$, hemoglobin $15.4 \mathrm{~g} / \mathrm{dl}$, platelets $230 \times 10^{9} / \mathrm{l}$, normal differential with absolute eosinophil count $0.2 \times 10^{9} / \mathrm{l}$ ). His disease course had been complicated by an esophageal stricture which was $12 \mathrm{~mm}$ in narrowest diameter (fig. 1a), requiring multiple balloon dilations up to $15 \mathrm{~mm}$ in diameter. Despite treatment with high-dose swallowed fluticasone ( $880 \mu \mathrm{g}$ twice daily) and then oral viscous budesonide (1 mg twice daily) over a 9-month period, he had ongoing dysphagia and persistently high levels of esophageal eosinophilia on follow-up biopsy $(>100$ eosinophils per high-power field) (fig. 1b). His dose of oral viscous budesonide was increased to $2 \mathrm{mg}$ orally twice daily and he was on this dose for 3 months prior to presentation. He was also treated with omeprazole $20 \mathrm{mg}$ daily. Six weeks prior to presentation, in an effort to treat his refractory esophageal eosinophilia and dysphagia, he was prescribed an oral prednisone taper: $40 \mathrm{mg}$ once daily for 2 weeks, then $30 \mathrm{mg}$ once daily for one week, then $20 \mathrm{mg}$ once daily for one week, then $10 \mathrm{mg}$ once daily for 2 weeks and finally $5 \mathrm{mg}$ once daily for 2 weeks. This taper was completed 1 week prior to his endoscopy and he reported some improvement in his dysphagia.

At the time of endoscopy, he complained of dyspnea and pleuritic chest pain over the preceding $48 \mathrm{~h}$, had focal tenderness of the left lower rib cage, and was febrile $\left(101.2^{\circ} \mathrm{F}\right)$. He was tachypneic but had normal oxygen saturation on pulse oximetry. Chest X-ray showed atelectasis and a possible infiltrate in the left lower lobe. Initial laboratory data were unremarkable (table 1), with the exception of an elevated D-dimer at $482 \mathrm{ng} / \mathrm{ml}$ (reference range: $0-229 \mathrm{ng} / \mathrm{ml}$ ). CT angiography of the chest demonstrated filling defects within the left upper lobe and left and right lower lobe segmental and subsegmental pulmonary arterial 
branches, consistent with PE (fig. 2a-c). Patchy opacities at the left lung base were felt to represent pulmonary infarct (fig. 2d). Doppler ultrasound of both legs was negative for deep venous thrombosis. He was started on a heparin drip and subsequently transitioned to warfarin. Thrombophilia workup (factor V Leiden, prothrombin 20210 gene mutation, protein $\mathrm{C}$, protein $\mathrm{S}$, and antithrombin activities, beta-2-glycoprotein I and anticardiolipin antibodies, and lupus anticoagulant) was negative for inherited and acquired hypercoagulable states (table 2). His only potential risk factors for VTE were grade 1 obesity, with a body mass index of $30.3 \mathrm{~kg} / \mathrm{m}^{2}$, and recent steroid use. There had been no preceding trauma, immobility, surgery or long-distance travel. Thus, this was interpreted as an unprovoked (idiopathic) VTE. He did not have peripheral blood eosinophilia, but did have an elevated IgE level of $242 \mathrm{kU} / \mathrm{l}$ (reference range: mean $13.2 \mathrm{kU} / \mathrm{l},+1 \mathrm{SD} 41,+2 \mathrm{SD}$ 127). He recovered well with no sequelae, but is being continued on long-term anticoagulation given his risk of recurrent VTE.

\section{Discussion}

In certain chronic inflammatory and autoimmune disease states, there appears to be increased risk for VTE. These include vasculitides, rheumatoid arthritis, systemic sclerosis, immune thrombocytopenic purpura, systemic lupus erythematosus, polymyositis and dermatomyositis [5]. Patients with inflammatory bowel disease have a 2- to 3-fold increased risk of VTE when compared to controls [2,3]. This risk is increased in patients with active disease and to a lesser degree in patients in remission [2], and there is also an increased risk of recurrent VTE [4]. Celiac disease, also characterized by chronic mucosal inflammation, has been associated with an increased risk of VTE in some studies [6], however the data are less conclusive than in inflammatory bowel disease and there is evidence that the risk might not be elevated [7].

As in inflammatory bowel disease and celiac disease, there is chronic mucosal inflammation in EoE. While there has been a case report of VTE in a patient with hypereosinophilia [8] and in a patient with eosinophilic gastroenteritis [9], to our knowledge there have been no previous reports of VTE occurring in patients with EoE. In the patient presented here, there was persistent and severe esophageal eosinophilia that was refractory to topical steroid therapy and resulted in active symptoms of dysphagia and recurrent esophageal strictures requiring repeated dilations. While the PE could have been a coincidence as a sporadic occurrence, possibly related to mild obesity or low-dose steroid use, it is intriguing to hypothesize that the chronic inflammation may have been a risk factor for VTE.

How might inflammation play a role in VTE in EoE, and are there any clues from patients with Crohn's and ulcerative colitis with concomitant VTE? The mechanisms behind the increased risk of thrombosis in patients with inflammatory bowel disease are as yet not well defined. Inflammatory bowel disease may be a hypercoagulable state due to inflammatorymediated upregulation of procoagulants, downregulation of anticoagulants or suppression of fibrinolysis $[5,10]$. Patients with inflammatory bowel disease have increased fibrinogen, and there are reports of decreased protein S activity [11], which could contribute to acquired thrombophilia. However, other evidence does not demonstrate the same procoagulant profile [12]. Other possible mechanisms include inflammation-mediated platelet activation [10] and corticosteroid use $[3,5]$. These abnormalities might not be expected to be present in most patients with EoE, given the absence of the systemic inflammation that is typically seen in inflammatory bowel diseases. However, there is some preliminary evidence that increased markers of eosinophil activity (e.g. eosinophil-derived neurotoxin and eotaxin-3) 
can be detected in the blood of patients with EoE, suggesting some systemic activity or effect [13].

It is possible that hypereosinophilia itself may be associated with hypercoagulability. One potential mechanism is that major basic protein, a protein found in eosinophilic cytoplasmic granules, inhibits the ability of thrombomodulin to bind to thrombin and activate protein C [14]. Activated protein C acts as an anticoagulant $[8,14]$; thus, if hypereosinophilia leads to inhibition of thrombomodulin, the balance might be shifted towards a procoagulant state. In addition, IgE may play a role. Patients with asthma and allergic rhinitis were noted to have platelet activation when exposed to dust mite allergens [15]. It is hypothesized that this process is mediated by antigen-specific IgE. Our patient did have a slightly elevated IgE level. However, although there is a strong association between EoE and atopic diseases, there are no reports documenting an association between atopic diseases themselves and VTE.

In conclusion, EoE is an increasingly recognized condition characterized by chronic mucosal inflammation and infiltration of the esophageal epithelium with eosinophils. We present the first case of a patient with EoE who developed a PE in the absence of other strong risk factors for VTE. This case highlights the importance of considering the diagnosis of VTE in the appropriate clinical setting in patients with EoE, and also raises the question of whether the PE in this patient was coincidental or a consequence of active EoE with severe and uncontrolled esophageal inflammation. If it is the latter, the mechanism is unclear, and the absolute risk of VTE in patients with EoE is unknown. Additional studies will be required to examine the prevalence of VTE in EoE to determine whether EoE is truly a risk for VTE and, if such an association is determined, explore the potential mechanisms of hypercoagulability in EoE.

\section{Acknowledgements}

This work was funded, in part, by NIH award numbers T32KD07634 (P.D.J.) and K23DK090073 (E.S.D.). The study sponsors had no role in the study design, collection, analysis or interpretation of the data.

\section{Authors' Contributions}

P.D.J.: data acquisition, data interpretation, manuscript drafting/revision; S.M.: clinical data interpretation, critical revision; E.S.D.: project conception and design, data interpretation, supervision, critical revision.

\section{Disclosure Statement}

No conflicts of interest exist for any of the authors. 
Jones et al.: Pulmonary Embolism in a Patient with Eosinophilic Esophagitis: Causal or Coincidental?

\section{References}

-1 Liacouras CA, Furuta GT, Hirano I, Atkins D, Attwood SE, Bonis PA, Burks AW, Chehade M, Collins MH, Dellon ES, Dohil R, Falk GW, Gonsalves N, Gupta SK, Katzka DA, Lucendo AJ, Markowitz JE, Noel RJ, Odze RD, Putnam PE, Richter JE, Romero Y, Ruchelli E, Sampson HA, Schoepfer A, Shaheen NJ, Sicherer SH, Spechler S, Spergel JM, Straumann A, Wershil BK, Rothenberg ME, Aceves SS: Eosinophilic esophagitis: updated consensus recommendations for children and adults. J Allergy Clin Immunol 2011;128:3-20.e6; quiz 21-22.

-2 Grainge MJ, West J, Card TR: Venous thromboembolism during active disease and remission in inflammatory bowel disease: a cohort study. Lancet 2010;375:657-663.

- 3 Kappelman MD, Horvath-Puho E, Sandler RS, Rubin DT, Ullman TA, Pedersen L, Baron JA, Sorensen HT: Thromboembolic risk among Danish children and adults with inflammatory bowel diseases: a populationbased nationwide study. Gut 2011;60:937-943.

4 Novacek G, Weltermann A, Sobala A, Tilg H, Petritsch W, Reinisch W, Mayer A, Haas T, Kaser A, Feichtenschlager T, Fuchssteiner H, Knoflach P, Vogelsang H, Miehsler W, Platzer R, Tillinger W, Jaritz B, Schmid A, Blaha B, Dejaco C, Eichinger S: Inflammatory bowel disease is a risk factor for recurrent venous thromboembolism. Gastroenterology 2010;139:779-787.

5 Zoller B, Li X, Sundquist J, Sundquist K: Risk of pulmonary embolism in patients with autoimmune disorders: a nationwide follow-up study from Sweden. Lancet 2012;379:244-249.

-6 Ludvigsson JF, Welander A, Lassila R, Ekbom A, Montgomery SM: Risk of thromboembolism in 14,000 individuals with coeliac disease. Br J Haematol 2007;139:121-127.

7 Johannesdottir SA, Erichsen R, Horvath-Puho E, Schmidt M, Sorensen HT: Coeliac disease and risk of venous thromboembolism: a nationwide population-based case-control study. Br J Haematol 2012;157:499-501.

-8 Sherer Y, Salomon 0, Livneh A, Pras M, Langevitz P: Thromboembolism in a patient with transient eosinophilia and thrombocytopenia. Clin Lab Haematol 2000;22:247-249.

-9 Santana Garcia S, Fuertes Martin A, Guerrero Peral AL, Aparicio Velasco J, Jimenez Lopez A: Eosinophilic gastroenteritis and pulmonary thromboembolism. A chance association? (in Spanish). An Med Interna 1995;12:73-75.

10 Yoshida H, Granger DN: Inflammatory bowel disease: a paradigm for the link between coagulation and inflammation. Inflamm Bowel Dis 2009;15:1245-1255.

-11 Koutroubakis IE, Sfiridaki A, Mouzas IA, Maladaki A, Kapsoritakis A, Roussomoustakaki M, Kouroumalis EA, Manousos ON: Resistance to activated protein $\mathrm{C}$ and low levels of free protein S in Greek patients with inflammatory bowel disease. Am J Gastroenterol 2000;95:190-194.

12 Jackson LM, O'Gorman PJ, O'Connell J, Cronin CC, Cotter KP, Shanahan F: Thrombosis in inflammatory bowel disease: clinical setting, procoagulant profile and factor V Leiden. QJM 1997;90:183-188.

13 Konikoff MR, Blanchard C, Kirby C, Buckmeier BK, Cohen MB, Heubi JE, Putnam PE, Rothenberg ME: Potential of blood eosinophils, eosinophil-derived neurotoxin, and eotaxin-3 as biomarkers of eosinophilic esophagitis. Clin Gastroenterol Hepatol 2006;4:1328-1336.

-14 Mukai HY, Ninomiya H, Ohtani K, Nagasawa T, Abe T: Major basic protein binding to thrombomodulin potentially contributes to the thrombosis in patients with eosinophilia. Br J Haematol 1995;90:892-899.

15 Jeannin P, Pestel J, Bossus M, Lassalle P, Tartar A, Tonnel AB: Comparative analysis of biological activities of Der p I-derived peptides on Fc epsilon receptor-bearing cells from Dermatophagoides pteronyssinussensitive patients. Clin Exp Immunol 1993;92:133-138. 
Jones et al.: Pulmonary Embolism in a Patient with Eosinophilic Esophagitis: Causal or Coincidental?

Table 1. Laboratory data obtained in a patient with PE and EoE

\begin{tabular}{lll}
\hline Laboratory study & Value & Reference range \\
\hline Sodium, mmol/l & 138 & $135-145$ \\
Potassium, mmol/l & 4.4 & $3.5-5$ \\
Chloride, mmol/l & 100 & $98-107$ \\
$\mathrm{CO}_{2}, \mathrm{mmol} / \mathrm{l}$ & 29 & $22-30$ \\
Blood urea nitrogen, mg/dl & 13 & $7-21$ \\
Creatinine, mg/dl & 1.11 & $0.70-1.30$ \\
Glucose, mg/dl & 92 & $65-179$ \\
Creatine kinase, U/l & 48 & $70-185$ \\
Creatine kinase MB, ng/ml & $<0.2$ & $0.0-6.0$ \\
Troponin I, ng/ml & $<0.034$ & $0.000-0.034$ \\
Prothrombin time, s & 11.7 & $9.7-12.6$ \\
International normalized ratio & 1.1 & \\
Activated partial thromboplastin time, $\mathrm{s}$ & 26.9 & $24.1-32.5$ \\
D-dimer, ng/ml & 482 & $0-229$ \\
White blood cell count, $\times 10^{9} / \mathrm{l}$ & 11.7 & $4.5-11$ \\
Absolute neutrophils, $\times 10^{9} / \mathrm{l}$ & 9.4 & $2.0-7.5$ \\
Absolute eosinophils, $\times 10^{9} / \mathrm{l}$ & 0.1 & $0.0-0.4$ \\
Absolute lymphocytes, $\times 10^{9} / \mathrm{l}$ & 1.5 & $1.5-5.0$ \\
Absolute monocytes, $\times 10^{9} / \mathrm{l}$ & 0.7 & $0.2-0.8$ \\
Absolute basophils, $\times 10^{9} / \mathrm{l}$ & 0.0 & $0.0-0.1$ \\
Hemoglobin, g/dl & 17.1 & $13.5-17.5$ \\
Hematocrit, $\%$ & 46.1 & $41.0-53.0$ \\
Platelet count, $\times 10^{9} / \mathrm{l}$ & 247 & $150-440$ \\
\hline
\end{tabular}

Laboratory evaluation at the time of presentation demonstrated normal electrolytes, cardiac enzymes, coagulation studies and complete blood count with differential. D-dimer was noted to be elevated to more than twice the upper limit of normal.

Table 2. Laboratory data from hypercoagulability workup obtained in a patient with PE and EoE

\begin{tabular}{lll}
\hline Laboratory study & Value & Reference range \\
\hline Factor V 1691G>A (factor V Leiden) & negative & negative \\
Prothrombin 20210 G>A gene mutation & negative & negative \\
Protein C activity, \% of normal & 117 & $68-170$ \\
Protein S activity, \% of normal & 101 & $64-147$ \\
Free protein S, \% of normal & 140 & $63-161$ \\
Antithrombin III activity, \% of normal & 97 & $83-123$ \\
Beta-2-glycoprotein I (IgA, IgM, IgG), U/ml & $<4.0$ & $<10$ \\
Anticardiolipin antibody, IgG, GPL & 4 & $0-23$ \\
Anticardiolipin antibody, IgM, MPL & 5 & $0-11$ \\
Lupus activated partial thromboplastin time, s & 41.0 & $35.4-50.8$ \\
Dilute Russell's viper venom time, s & 39.3 & $0-47.1$ \\
\hline
\end{tabular}

Hypercoagulability workup was within normal limits. 


\section{Case Reports in
Gastroenterology}

\begin{tabular}{l|l}
\hline \multicolumn{2}{l}{ Case Rep Gastroenterol 2013;7:82-88 } \\
\hline DOI: $10.1159 / 000350187$ & $\begin{array}{l}\text { ○ 2013 S. Karger AG, Basel } \\
\text { www.karger.com/crg }\end{array}$ \\
\hline
\end{tabular}

Jones et al.: Pulmonary Embolism in a Patient with Eosinophilic Esophagitis: Causal or Coincidental?
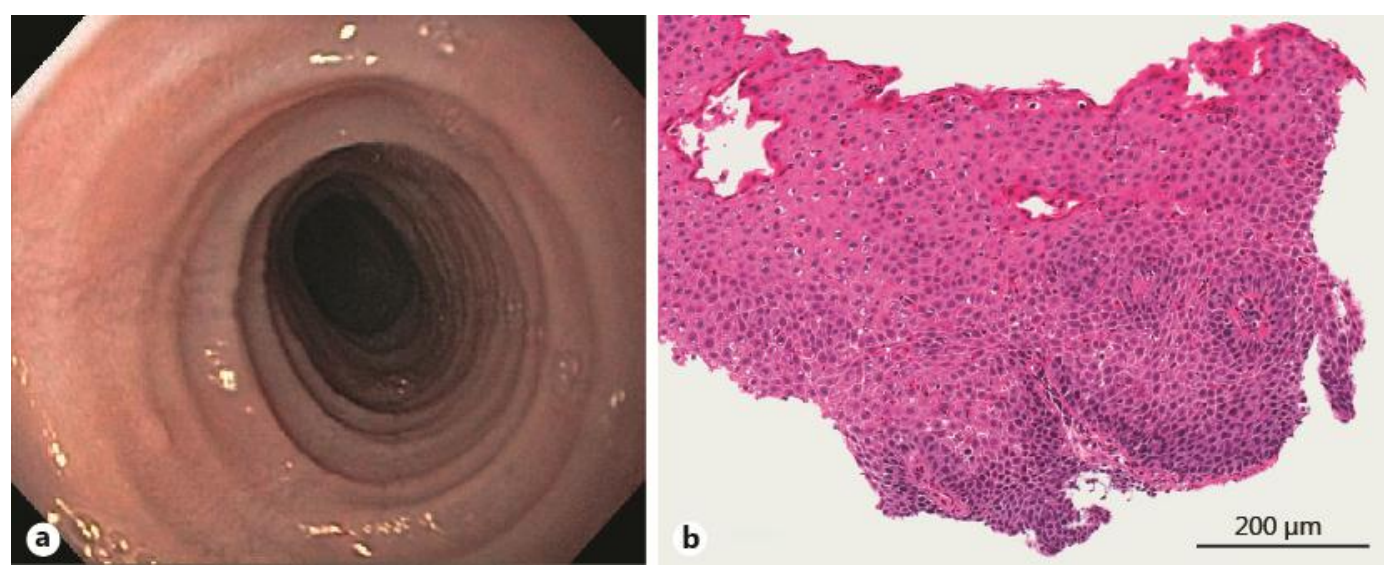

Fig. 1. Endoscopic and histologic images showing active EoE. a The endoscopic view shows a narrowcaliber and strictured proximal esophagus with prominent rings, linear furrows, and decreased mucosal vascularity. b The histologic view $(40 \times)$ of the esophageal biopsy specimen demonstrates a marked eosinophilic infiltrate in the mucosa as well as basal layer hyperplasia and spongiosis.
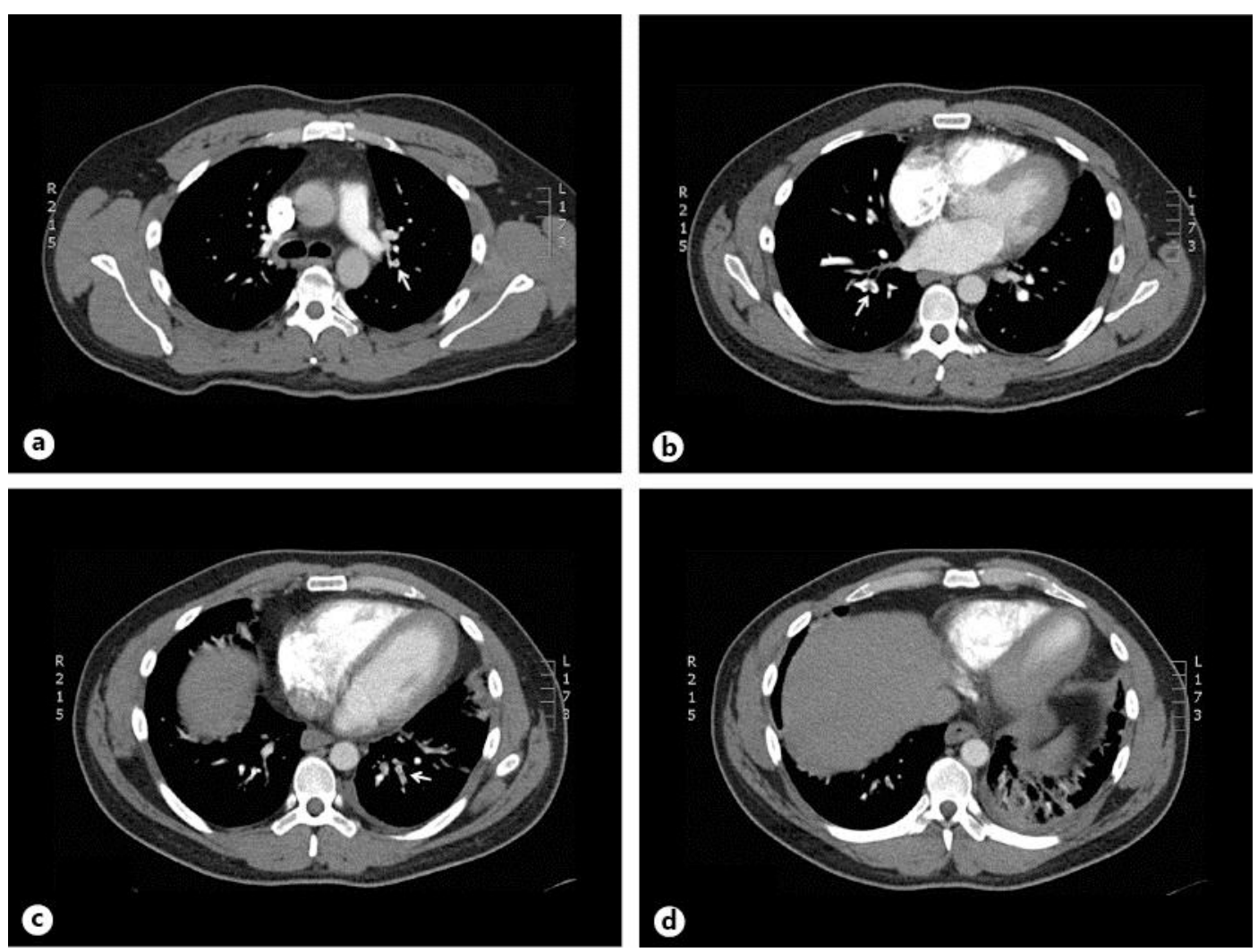

Fig. 2. CT angiography demonstrating multiple segmental pulmonary emboli and subsequent pulmonary infarct. a A filling defect consistent with PE is noted in the left lower lobe segmental artery (arrow). b A filling defect consistent with PE is noted in the right lower lobe segmental artery (arrow). c Another filling defect noted in the left lower lobe segmental artery (arrow). d Patchy opacities seen in left lower lobe most consistent with pulmonary infarct. 